\title{
As políticas públicas de coleta seletiva no município do Rio de Janeiro: onde e como estão as cooperativas de catadores de materiais recicláveis?
}

\author{
Vinícius Ferreira Baptista \\ Universidade Federal Rural do Rio de Janeiro
}

\begin{abstract}
O artigo é um estudo sobre políticas públicas voltadas à coleta seletiva operacionalizada por cooperativas de catadores de materiais recicláveis no município do Rio de Janeiro, identificando suas perspectivas e limites. Contextualizamos a Política Nacional de Resíduos Sólidos e a problematização que envolve as cooperativas de catadores. Situamos as regras gerais e indicações normativas das leis e decretos, planos e programas criados. Destacamos dados sobre a coleta seletiva no município do Rio de Janeiro. Por fim, apresentamos os resultados preliminares da pesquisa de campo realizada junto aos gestores de cooperativas. Apontamos, enfim, que as políticas públicas de coleta seletiva trazem instrumentos que não são percebidos em sua totalidade pelos atores envolvidos, o que implica a sua não pactuação e, por consequência, a não utilização plena das vantagens induzidas pela política.
\end{abstract}

Palavras-chave: política nacional de resíduos sólidos; coleta seletiva; catadores de materiais recicláveis; cooperativas.

Políticas públicas de recogida selectiva en la ciudad de Rio de Janeiro: ¿dónde y cómo están las cooperativas de recolectores de materiales reciclables?

El artículo es un estudio acerca de las políticas públicas para la recogida selectiva de residuos sólidos por parte de las cooperativas de recolectores de materiales reciclables en el municipio de Río de Janeiro, identificando sus potenciales y límites. Contextualizamos la Política Nacional de Residuos Sólidos y la problematización que envuelven las cooperativas de recolectores. Primeramente, situamos las normas generales y las indicaciones normativas de leyes y decretos, planos y programas creados. Resaltamos datos generales de la recogida selectiva en el municipio de Río de Janeiro. Por último, se presentan los resultados preliminares de la investigación de campo llevada a cabo con los responsables de las cooperativas investigadas. Apuntamos, en fin, que las políticas públicas de recogida selectiva tracen instrumentos que no se perciben en su totalidad por los actores involu-

DOI: http://dx.doi.org/10.1590/0034-76121603

(cc) BY-NC

Artigo recebido em 16 jun. 2013 e aceito em 11 ago. 2014. 
crados, lo que implica su no pacto, y por lo tanto, na non utilización plena do uso de las ventajas inducidas por la política.

Palabras clave: política nacional de residuos sólidos; reciclaje de residuos; recolectores de materiales reciclables; cooperativas.

Public policies of selective waste collection in the municipality of Rio de Janeiro: where and how are the cooperatives of collectors of recyclable materials?

The paper is a study of public policies for selective waste collection operationalized by cooperatives of pickers of recyclable materials in the municipality of Rio de Janeiro, identifying its perspectives and limits. We contextualize about the Solid Waste National Policy and problematize the situation about cooperatives of pickers. After, we situate the general rules and normative indications of Laws and Decrees, plans and programs created. Next, we highlight general data collected at the municipality of Rio de Janeiro. Finally, we present the preliminary results of the field research conducted with the managers of cooperatives. We have noted, finally, that there are public policies that bring instruments that are not perceived in its entirety by the actors involved, which implies in their non-pact and therefore, not in the full use of the advantages induced by the policy.

KEywords: solid waste national policy; selective waste collection; pickers of recyclable material; cooperatives.

\section{Introdução}

O artigo é um estudo preliminar das políticas públicas voltadas à coleta seletiva operacionalizada por cooperativas de catadores de materiais recicláveis no município do Rio de Janeiro, identificando suas perspectivas e limites. Em primeiro lugar, expomos considerações iniciais sobre a Política Nacional de Resíduos Sólidos (PNRS) e políticas de coleta seletiva. Posteriormente, situamos, por meio de dados obtidos em documentos governamentais, a situação da coleta seletiva no município do Rio de Janeiro. Em seguida, apresentamos os resultados preliminares da pesquisa de campo realizada junto aos gestores de cooperativas a fim de investigar a percepção dos mesmos sobre as políticas públicas, o cenário, as positividades e negatividades da coleta seletiva. Enfim, antecipamos uma interpretação provisória, cuja base aponta a PNRS como uma política pública que traz instrumentos que não são percebidos em sua totalidade pelos atores envolvidos, o que implica a sua não pactuação e, por consequência, a não utilização plena das vantagens induzidas pela política. A pesquisa de campo junto aos gestores foi enfática: eles têm pouco conhecimento sobre o conteúdo da PNRS, mas sabem todo o processo técnico da coleta seletiva e da gestão dos resíduos. Por outro lado, as cooperativas apresentam conjuntura instável de estrutura. A PNRS não é pactuada plenamente por todos os atores e, dessa forma, perde a capacidade de inclusão social, pelo distanciamento entre os gabinetes dos formuladores da política e os galpões da cooperativa. 


\section{Materiais e métodos}

Iniciamos o estudo a partir de um resgate acerca dos resíduos sólidos urbanos (RSU) e das políticas que tratam sobre o tema. Temos como destaque a PNRS. Trazemos dados estatísticos acerca da problematização da gestão dos resíduos e como essa temática vem sendo debatida na gestão pública. Esta pesquisa pauta-se pela análise qualitativa de políticas públicas e de dados obtidos juntos a órgãos governamentais e não governamentais em âmbito nacional, mas com um foco no município do Rio de Janeiro. Com o objetivo de realizar um estudo contundente acerca da realidade da política, optamos pela pesquisa de campo junto a três cooperativas de catadores de materiais recicláveis, seguido de um roteiro de entrevista pautado pela estrutura semiaberta. Quanto à análise das entrevistas, deu-se ênfase à análise do conteúdo dos gestores de cooperativas.

\section{A Política Nacional de Resíduos Sólidos: breve resumo}

A Lei no 12.305/2010, que institui a PNRS, prenuncia ser um marco no que tange à gestão eficiente dos resíduos sólidos. Ela já começa a surtir efeitos práticos, uma vez que obriga municípios a formularem planos de gestão de resíduos, assim como induz os mesmos a erradicarem os "lixões". Ela promete ser um marco justamente pelo fato de que a gestão dos resíduos, pelo menos no caso brasileiro, muitas das vezes não foi planejada por meio de planos e, na maioria dos municípios brasileiros, com a utilização de lixões sem as mínimas condições e estruturas sanitárias.

O processo de elaboração da PNRS em projetos de lei data de 1989, quando ainda estava sob a forma do Projeto de Lei do Senado no 354/1989, que disporia, inicialmente, sobre os resíduos de saúde. Vários projetos seriam apensados ao PLS no 354/1989, que transformariam o escopo do projeto, ampliado para além dos resíduos de saúde. Tal PL seria transformada no PL no 203/1991, tramitando na Câmara dos Deputados até 2010, quando seria sancionado pela Lei no 12.305/2010.

Em seu art. 1ํㅡ a PNRS dispõe de princípios, objetivos e instrumentos relativos à gestão integrada e ao gerenciamento de resíduos sólidos, incluindo os perigosos, as responsabilidades dos geradores e do poder público. O art. 25 afirma que o poder público, o setor empresarial e a coletividade são responsáveis pela efetividade das ações voltadas para assegurar a observância da PNRS, e o art. 30 institui a responsabilidade compartilhada pelo ciclo de vida dos produtos entre o setor público, a iniciativa privada e a sociedade civil, em que se objetivam a compatibilidade entre os interesses entre agentes econômicos e sociais, e entre os processos de gestão empresarial e os de gestão ambiental, com vistas ao desenvolvimento de estratégias sustentáveis.

A PNRS indica, por meio do art. 3ํㅡㄹ Inciso XI, que a Gestão Integrada de RSU compreende o "conjunto de ações voltadas para a busca de soluções para os resíduos sólidos, de forma a considerar as dimensões política, econômica, ambiental, cultural e social, com controle social e sob premissa do desenvolvimento sustentável" (Brasil, 2010). Esse trecho 
do texto legal indica a reorganização na forma como os resíduos sólidos são entendidos e "tratados"; a consideração mais ampla e complexa, que envolve questões para além do marco da saúde pública, se traduz no momento em que os resíduos são dotados de valor social, econômico e ambiental.

Há de se chamar a atenção de que a PNRS não se restringe aos instrumentos de comando e controle, mas os "supera", pautando-se pela proatividade, estruturação das responsabilidades e gestão compartilhada. A PNRS "institui um modelo participativo que delimita, mas também cobra a aplicação das responsabilidades e apresenta punições pelo descumprimento", com aplicação subsidiária da tríplice responsabilidade ambiental (responsabilidade civil objetiva e solidária, administrativa e penal) (Jardim, Yoshida e Machado Filho, 2012:4).

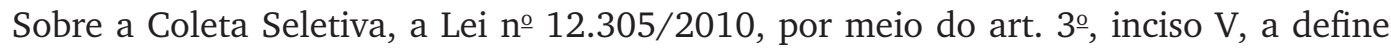
como a "coleta de resíduos sólidos previamente segregados conforme sua constituição ou composição". A Coleta Seletiva é um dos principais instrumentos da PNRS prescritos no capítulo III da referida lei, em que, segundo o $§ 1^{\circ}$ do art. 18, os municípios que a implantarem com a participação de cooperativas ou outras formas de associação de catadores de materiais reutilizáveis e recicláveis formadas por pessoas físicas de baixa renda terão prioridade ao acesso aos recursos da União.

O estímulo à Coleta Seletiva é facilitado por meio do art. 35, que apresenta as obrigações dos consumidores, quando estabelecido, no município, o sistema de Coleta Seletiva proposto pelo plano municipal de gestão integrada de resíduos sólidos. Faculta-se ao poder público a possibilidade de instituir incentivos econômicos aos consumidores que participarem do sistema de coleta seletiva, na forma de lei municipal (Brasil, 2010). No art. 42, com os instrumentos econômicos, o poder público poderá instituir medidas indutoras e linhas de financiamento para atender prioritariamente, entre outros, a estruturação de sistemas de coleta seletiva e de logística reversa, prioritariamente em parceria com cooperativas ou outras formas de associações. Podemos observar que a PNRS procura trazer mecanismos voltados à facilitação e manutenção de parcerias que se atentem à pactuação da política como um todo entre os atores.

A PNRS tem como uma de suas bases o Decreto Federal oㅗ 5.940/2006, que institui a separação dos resíduos recicláveis descartados pelos órgãos e entidades da administração pública federal direta e indireta, na fonte geradora, e a sua destinação às associações e cooperativas dos catadores de materiais recicláveis (art. $1^{\circ}$ ). Dessa forma, a lei procurar trazer as cooperativas de catadores à gestão dos RSU.

$\mathrm{O}$ art. 36 da PNRS aponta as responsabilidades do titular dos serviços públicos de limpeza, em que havendo o plano municipal de gestão integrada de resíduos sólidos, o mesmo deverá: adotar procedimentos para o reaproveitamento de resíduos reutilizáveis e recicláveis oriundos dos serviços de limpeza urbana e manejo de resíduos sólidos; estabelecer um sistema de coleta seletiva; estimular os agentes econômicos e sociais a adotar medidas que visem a viabilidade do retorno de resíduos reutilizáveis e recicláveis coletados na limpeza urbana ao ciclo produtivo; a implantação da compostagem para resíduos orgânicos, entre outras ações (Brasil, 2010). O titular dos serviços públicos de limpeza terá de dar prioridade à organização 
e ao funcionamento de cooperativas ou de outras formas de associação de catadores de materiais formadas por pessoas físicas de baixa renda, bem como sua contratação. Percebe-se o caráter de inclusão social na PNRS.

\section{Os catadores}

O discurso mais comum no que se referia a cooperativas de catadores era o de que as mesmas eram compostas por "desempregados". Tal terminologia, cooperativas compostas por "desempregados", esteve também associada à confusão aos termos "trabalho" e "emprego". Os catadores desempenham uma atividade produtiva, ou seja, concretizam trabalho, pois conseguem "construir" valor sobre determinado resíduo e inseri-lo novamente na cadeia produtiva. ${ }^{1}$ A visão negativa sobre o processo produtivo do catador é corroborada por Bosi (2008:102), ao afirmar que "o trabalho do catador não tende a ser apreendido e interpretado como trabalho explorado, que gera mais-valia e que é organizado e articulado, em larga medida, em função do processo de acumulação do capital".

Contudo, os catadores não são "empregados" - pois se estão em associações ou cooperativas, são sócios e não possuem vínculo empregatício. Por outro lado, na visão popular são considerados "desempregados" e necessitam ser incluídos no mercado. E assim são vistos na construção de políticas públicas por muitos gestores públicos.

Conceição (2003:132) situa que "o ator principal desse cenário é o catador de lixo, que das ruas tira o seu sustento e, agora, para tentar livrar-se dos sucateiros, seus 'sanguessugas' e da exclusão social que este modelo capitalista lhes impõe, está formando cooperativas de recicladores de lixo".

As pessoas que trabalham com resíduos sólidos, especificamente os catadores, lidam diariamente com condições extremamente desfavoráveis e precárias em termos de garantias legais (trabalhista e/ou assistencial). São operários terceirizados da indústria da reciclagem. Para Pereira e Teixeira (2011), os catadores se situam na base da cadeia produtiva dessa indústria da reciclagem e, uma vez inseridos precariamente, as indústrias recicladoras é que englobam os grandes lucros, e muitas delas se valem do discurso da Responsabilidade Socioambiental para esconder basicamente três grandes problemas centrais: a necessidade de se repensar o consumo; a mudança dos padrões de produção, descarte e obsolescência; e, por fim, a exploração do trabalho de indivíduos marginalizados pela sociedade e pelo poder público.

Os mesmos autores criticam certas políticas engendradas pelo poder público em grande parte das cidades brasileiras, como "políticas higienistas", pelo fato de os catadores terem

\footnotetext{
${ }^{1} \mathrm{O}$ termo "construir" seria mais adequado, pois "extrair" valor, já consolidado na literatura, não se aplicaria nesse caso, uma vez que um resíduo descartado já teve, a priori, seu valor extraído. Os catadores "constroem” valor agregado e não extraem.
} 
sido e ainda serem percebidos como "delinquentes" e/ou "mendigos" que "sujam" os centros urbanos (Pereira e Teixeira, 2011:896).

No Brasil encontram-se, há mais de 50 anos, catadores nas ruas das cidades, sobrevivendo da coleta e da venda de materiais recicláveis. Estima-se que mais de 500 mil $^{2}$ pessoas circulam com seus carrinhos no país. A maior parte desses trabalhadores ficou desempregada na mudança do sistema produtivo e sobrevive da catação de recicláveis que vêm agregando valor desde a década de 1990 (Besen, 2008:5).

A cadeia produtiva dos recicláveis brasileira é admirada, com centenas de empresas que se autointitulam socialmente responsáveis, mas que, muitas vezes, se beneficiam de um ciclo vicioso de exploração do trabalho, que nos moldes geralmente empreendidos caracteriza a coleta seletiva e os catadores.

Há casos sérios de violação de direitos humanos em que esses trabalhadores são submetidos a horas de trabalho a fio sem qualquer salubridade, há casos de servidão por dívida ao comprador, vínculos por meio de pequenos vícios, trabalho infantil e análogo à servidão. [...] Verdadeiros cartéis de compradores submetem catadores à condição de mão-de-obra barata. [...] Hoje, esse é o retrato da cadeia produtiva no Brasil, da qual os catadores são agentes principais, mas também os que menos se beneficiam dela. (Jardim, Yoshida e Machado Filho, 2012:423)

Ainda que o catador (antes pensado como indivíduo) integre uma cooperativa, visto agora como corpo coletivo, em uma tentativa de fuga em face da exploração econômica, esta ainda poderia continuar dependendo das condições das próprias cooperativas, mas também do sistema que organiza a coleta seletiva, uma vez que

as indústrias que compram os materiais reciclados são poucas (formam um mercado oligopsônio), exigem grandes volumes para negociarem e estes volumes só são alcançados, muitas vezes, por sucateiros que estão há mais tempo no mercado e financiados pela própria indústria. (Conceição, 2003:133)

Essa figura, o sucateiro (convencionalmente denominado "atravessador"), atravessa a produção do catador, por possuir infraestrutura, logística e capital de giro, o que o catador individual e outras cooperativas não têm. Tal sucateiro não é percebido na formulação de políticas voltadas à coleta seletiva. Por conta de tais fatores, ele pode armazenar por mais tempo e vender seu material ao mercado em tempos favoráveis — entenda-se falta destes no mercado e maior procura, além de ser mais resistente às flutuações do próprio mercado. Já os catadores e as cooperativas não têm tais fatores em níveis de equivalência — geralmente não o têm — e precisam distribuir rendimentos aos seus cooperados, ou seja, possuem menor capacidade de vender em momentos adequados. Conceição (2003:133-134) aponta que tal conjuntura

${ }^{2}$ O Movimento Nacional de Catadores de Materiais Recicláveis (MNCR) estima em 800 mil (Jardim, Yoshida e Machado Filho, 2012:422). 
leva as cooperativas a venderem seus produtos a um preço muitas vezes abaixo do que aquele pago no mercado e, considerando-se o fato de que não conseguem acumular um volume maior para venda, pois não possuem espaço para isso, compreende-se o porquê as cooperativas ficam nas "mãos" dos sucateiros e indústrias controladoras deste mercado.

Como então mudar esse quadro de exploração? Como trazer a liberdade de se ter o trabalho, por meio do próprio trabalho? Como a emancipação poderia ocorrer pelo trabalho? Conceição (2003) situa que deveriam ser criadas políticas voltadas ao âmbito econômico, político e social acompanhadas de outras políticas educacionais aos cooperativados, assistência médica e infraestrutura destinada a proporcionar o desenvolvimento de integração dos catadores, e que sejam extensivas aos familiares. Ou seja, as políticas devem ser inclusivas em relação a possíveis beneficiários e integrativas em relação a instituições e atores.

As cooperativas e associações de catadores visam à prestação de um serviço público à sociedade. São organizações sem fins lucrativos. Propõem-se ao trabalho, seu desenvolvimento e a ajustar sua execução. Entretanto, necessitam de aparelhos legais, econômicos e institucionais para que possam manter-se e para que seus associados tenham a digna contraprestação pelo seu trabalho; para a evolução da própria prestação de seus serviços; e também para que o valor econômico, gerado por eles, retorne a eles e não seja apropriado como mais-valia em favor de algum atravessador.

Os catadores, reunidos em cooperativas ou associações, têm pela frente o grande desafio de conciliar os aspectos cooperativos (solidariedade, igualdade, liberdade) com a competitividade do mercado da livre-concorrência. Há uma latente defasagem nos termos de troca e não há condições equivalentes de competição. Neste contexto, qual o papel do Estado e dos próprios catadores como atores políticos dentro das políticas públicas?

Apesar de os empreendimentos solidários crescerem progressivamente no Brasil, eles vêm enfrentando uma série de obstáculos que impedem a consolidação do modelo, já que não há forte atuação do poder público e organização própria dos catadores em níveis mais amplos.

Interessa destacar que, durante o primeiro mandato de Fernando Henrique Cardoso, o Plano Diretor de Reforma do Aparelho de Estado, sob o comando do Ministério da Administração e Reforma do Estado (Mare), chefiado por Luiz Carlos Bresser-Pereira, reorganizaria a administração pública, incorporando organizações sociais para assumir as atividades públicas não estatais. Esse Plano, contudo, não foi implantado como um todo, "uma vez que contou com a resistência de parte dos servidores públicos e dos partidos de oposição" (Leite Junior, 2009:65-66). O Mare seria extinto cinco anos depois e o Plano Diretor seria progressivamente abandonado. A sua base, todavia, foi absorvida em diversos órgãos da administração pública, dando frutos na gestão de várias instituições do setor público. Empreendia-se uma reorganização das normas e instituições.

O Mare, em essência, reorganizou também as políticas públicas, não somente pelo fato de as organizações sociais estarem mais próximas ao poder público, mas por estas assumirem a prestação de serviços públicos, antes ofertados pelo Estado. Nesse ponto, percebe-se a clara separação entre o núcleo que "pensa" e elabora a política e os executores da mesma. A pala- 
vra-chave era "governança" (Matias-Pereira, 2010) e o objetivo era apoiar uma administração pública que se propõe a oferecer serviços e não a gerir programas, pregando os princípios da confiança e delegação de poderes, atribuições e responsabilidades.

A influência do Mare na construção das políticas públicas posteriores foi fundamental pelo fato de incorporar atores antes "fora" dos espaços públicos de negociação, mas também de incluí-los no sistema de elaboração, implantação, monitoramento e avaliação das políticas públicas. Não há como dissociar as políticas públicas de coleta seletiva implantadas após os anos 2000 do contexto da criação do Mare, por tal modelo ser uma das bases dessas políticas. Os programas de coleta seletiva nos municípios brasileiros são, em sua maioria, em parceria com cooperativas e associações de catadores de materiais recicláveis. Aqui, não há uma delegação da prestação dos serviços, pois a gestão dos resíduos é constitucionalmente uma atribuição dos municípios. Por outro lado, uma parte dessa gestão foi organizada participativamente entre diversos atores, com maior responsabilidade sobre as cooperativas de catadores.

Mas há de se ter em consideração que a inclusão de atores no âmbito da gestão das políticas não significa necessariamente maior articulação na tomada de decisão. Pelo contrário. Ainda que o Mare tenha descentralizado muitas das atribuições no campo das políticas públicas, ainda persiste a discrepância entre os que as "pensam" e os que as "executam". A inclusão de atores nesse campo deu-se mais na execução do que na elaboração das políticas. Este último ainda permanece "fechado" às negociações, o que se reflete em políticas públicas Up to Bottom, rompendo a ligação entre o pensar e o executar, como se fossem dois momentos diferentes da elaboração da política. E, no âmbito da coleta seletiva, muitas políticas são assim, conforme pode ser observado em conversas com gestores das cooperativas.

O modelo de coleta seletiva e as políticas públicas voltadas ao tema ainda padecem dessa dissociação entre os núcleos que pensam e executam as políticas. E isso impacta o desenvolvimento das atividades das cooperativas, por suas necessidades não serem observadas no momento da criação das políticas. O que seria um tanto óbvio, uma vez que, se os afetados pela política não são parte do processo de elaboração, muitas partes significativas do processo não são consideradas, o que enfraquece a política pública em si.

Como indicado anteriormente, se pensarmos no exemplo dos sucateiros, percebemos o distanciamento entre formuladores e executores de políticas. A figura do sucateiro é conhecida entre os catadores, as cooperativas e revendedores de materiais triados pelas cooperativas. Uma política pública deveria observar essa questão, mas, como há um distanciamento, os formuladores não possuem conhecimento acerca desses atores "invisíveis" ao sistema da coleta seletiva. E, mais uma vez, cria-se uma política que não observa atores que atravessam esse sistema, enfraquecendo as possibilidades dessa política.

Para Besen (2008:11), "a opção do modelo brasileiro pela organização dos catadores em cooperativas enfrenta o desfio de viabilizar empreendimentos solidários, em mercados capitalistas e globalizados". Entre os principais desafios estão, no marco legal, a necessidade de amparo para o trabalho autogestionário, a regulação do trabalho coletivo, a cobertura ao associativismo e cooperativismo, a dinamização de outras formas coletivas de trabalho, os tributos, a desburocratização de procedimentos administrativos. 
Entre outros problemas, destacam-se a baixa coleta de material, comparado ao que é produzido; a baixa capacidade de inclusão de catadores avulsos, promoção de renda e benefícios aos associados; remuneração inadequada pelos serviços prestados; falta de capacidade de investimentos, crédito e capital de giro; infraestrutura e gestão precárias (Besen, 2008). São problemas que as cooperativas, por si só, não conseguem resolver e necessitam de ações do poder público para o ajuste de tal conjuntura, que torne a situação mais favorável à criação, permanência e reprodução de cooperativas e/ou outras formas de associações de trabalho.

Os sócios cooperativados, além de proprietários, são provedores da força de trabalho, ou seja, há uma duplicidade de identidade do cooperado. A dupla qualidade dos membros da cooperativa explica-se porque esse tipo de sociedade inverte os meios e fins que caracterizam as sociedades empresariais não cooperativas: enquanto nestas a atividade societária é um alcance dos fins empresariais (lucro), nas cooperativas, as atividades empresariais são o meio de alcance do objetivo societário (acréscimo de renda direta ou indireta) (Krueger, 2003:59).

\section{As políticas que envolvem a coleta seletiva no município do Rio de Janeiro}

No município do Rio de Janeiro, a exigência do Plano Municipal de Gestão Integrada de Resíduos Sólidos (PMGIRS) surge com a sanção da Lei Municipal no 4.969/2008, que dispõe sobre objetivos, instrumentos, princípios e diretrizes para a gestão no âmbito do município. Por meio do art. 6o estabelece que cabe ao município elaborar o seu Plano de Gestão. Segundo consta no PMGIRS do Rio de Janeiro, a coleta seletiva de materiais recicláveis, realizada porta a porta nos principais logradouros de 41 dos 160 bairros do município, permite que $200 \mathrm{t} / \mathrm{dia}^{3}$ sejam encaminhadas às esteiras de catação da Usina de Reciclagem do Caju, onde trabalham 110 cooperados, recuperando cerca de 20 t/dia de recicláveis. Ainda segundo o documento, "a quantidade de recicláveis recuperada pelo sistema de coleta seletiva e pelas cooperativas de catadores atingiu 7.797 toneladas em todo o ano de 2011. Isto equivale a apenas $4 \mathrm{~g}$ por pessoa por dia" (Rio de Janeiro, 2012:33).

Alguns resultados da pesquisa Coselix $2005^{4}$ (Ribeiro et al., 2006, apud Besen, 2008:3-4), que elaborou e aplicou indicadores de sustentabilidade em 11 programas e 32 organizações de catadores na Região Metropolitana de São Paulo (RMSP), identificaram grandes desafios a serem enfrentados para a consolidação desses programas.

No que se refere à dimensão ambiental verifica-se que as quantidades de materiais recicláveis coletadas e desviadas dos aterros sanitários ainda são baixas se comparadas ao total de resíduos domiciliares produzidos, ou mesmo às quantidades desviadas pelos catadores autônomos. (Besen, 2008:4)

\footnotetext{
${ }^{3} \mathrm{O}$ Estado do Rio de Janeiro produz aproximadamente 12 mil toneladas de lixo por dia. Desse total, estima-se que quase $80 \%$ vão parar em lixões sem qualquer tipo de tratamento (SEA).

${ }^{4}$ Coordenada pela Faculdade de Saúde Pública da Universidade de São Paulo (USP).
} 
Junto ao decreto municipal está o Decreto no 40.645/2007, de 8 de março de 2007, do estado do Rio de Janeiro que, nos moldes do Decreto Federal no 5.940/2006, institui a separação dos resíduos recicláveis descartados pelos órgãos e entidades da administração pública estadual direta e indireta, na fonte geradora, e a sua destinação às associações e cooperativas dos catadores de materiais recicláveis (Rio de Janeiro, 2007). Nota-se o caráter incremental e texto idêntico dos três decretos.

Há de se contar também com a Lei no 3.755/2002, do estado do Rio de Janeiro, a Lei La Provita, que autoriza o Poder Executivo a financiar e/ou subsidiar a formação de cooperativas com a finalidade de coletar materiais inorgânicos passíveis de reciclagem. Por meio do art. $2^{\circ}$ o Poder Executivo poderá oferecer aos interessados em sua formação o fornecimento de todos os equipamentos necessários à execução dos seus objetivos. E pelo art. 4º, para a constituição das cooperativas de que trata essa lei, serão gratuitos os atos de registro na Junta Comercial do Estado do Rio de Janeiro, podendo o Poder Executivo estender a gratuidade a outros atos (Rio de Janeiro, 2002).

Por fim, destaca-se a Lei no 4.191/2003, que dispõe sobre a política de resíduos sólidos do estado do Rio de Janeiro. A lei visa, segundo o seu art. 1ำ, estabelecer princípios, procedimentos, normas e critérios referentes a geração, acondicionamento, armazenamento, coleta, transporte, tratamento e destinação final dos resíduos sólidos no estado do Rio de Janeiro. Uma medida regulatória é apresentada no art. 7o, o qual conta que as atividades geradoras de quaisquer tipos de resíduos sólidos ficam obrigadas a cadastrarem-se junto ao órgão estadual responsável pelo licenciamento ambiental (Rio de Janeiro, 2003). Os instrumentos e objetivos são muito semelhantes à PNRS. Por outro lado, a lei do estado do Rio de Janeiro apresenta um caráter mais incisivo quando comparada à PNRS, pelo fato de a União ter de legislar normas gerais, diferentemente dos estados, que podem legislar mais especificamente.

O PMGIRS prevê "extensa capacitação dos catadores para a autogestão das Centrais de Triagem, incluindo a gestão financeira e contábil, segurança do trabalho e patrimonial, saúde ocupacional e ambiental, mercado de materiais recicláveis e comercialização em rede, dentre outras" (Rio de Janeiro, 2012:37).

A Coleta Seletiva no município do Rio de Janeiro é coordenada pela Companhia Municipal de Limpeza Urbana (Comlurb) e pela Secretaria Municipal do Meio Ambiente (Smac), fazendo parte do Plano Estratégico do município (2012-14). No âmbito estadual, a Coleta Seletiva é coordenada pela Secretaria de Estado do Ambiente (SEA) e pelo Instituto Estadual do Ambiente (Inea).

\section{Dados sobre a geração de resíduos e coleta seletiva no Rio de Janeiro}

De acordo com a Pesquisa Nacional de Saneamento Básico (PNSB) de 2008, dos 5.564 municípios brasileiros, 994 deles (18\%) praticavam a coleta seletiva; por outro lado, em 5.024 municípios, a coleta seletiva não existia oficialmente. As primeiras informações levantadas pela PNSB de 1989 identificaram, naquele ano, a existência de 58 programas de coleta seletiva no 
país e depois, na PNSB 2000, no mesmo ano, esse número cresceu para 451 (IBGE, 2010). Outros dados situam que, de 5.564 municípios brasileiros, apenas 643 (aproximadamente $12 \%$ ) destinaram os resíduos às unidades de triagem de resíduos recicláveis.

Especificamente quanto ao município do Rio de Janeiro a PNSB situa que há 22 municípios com serviço de coleta seletiva, oito deles com abrangência por todo o município. Desses 22 municípios, em 11 deles os comerciantes de materiais recicláveis são os principais receptores finais. Em apenas oito desses 22 municípios a aplicação dos recursos provenientes da coleta seletiva é destinada à manutenção do programa (IBGE, 2010). Já a Abrelpe (2012) destaca que, na região Sudeste, há 1.336 municípios com iniciativas de Coleta Seletiva.

Nos 24 municípios do estado do Rio de Janeiro em que o manejo de resíduos sólidos é realizado com participação de catadores nas ações de coleta seletiva, em 17 (70\%), a forma de participação das mesmas ocorre por meio de cooperativas ou associações. Quanto às cooperativas de catadores, em 51\% dos 92 municípios do Rio a entidade pública responsável não tem conhecimento quanto à atuação de catadores na área urbana e em 70\% deles a entidade pública não tem conhecimento quanto à atuação de catadores nas unidades de disposição de resíduos no solo (IBGE, 2010).

Dados da Abrelpe situam que foram coletadas, em 2011, no estado do Rio de Janeiro, 20.305 t/dia de RSU ou 1,303 kg/hab/dia. Especificamente na cidade do Rio de Janeiro, foram coletados $8.263 \mathrm{t} /$ dia de RSU ou 1,3 kg/hab/dia. A disposição final em Aterros Sanitários constitui a maior parte da forma realizada (68\% em 2011), sendo tendência de aumento, pois esse mesmo índice foi de 67,1\% em 2010. Quanto à disposição em lixões, teve uma queda de 10,3\% em 2010 para 10\% em 2011. A disposição em aterros controlados também caiu de $22,6 \%$ para $22 \%$ de 2010 para 2011, o que indica que os RSU passaram a ser dispostos em Aterros Sanitários.

Dados constantes no PMGIRS indicam que os resíduos gerados na cidade do Rio de Janeiro e que foram encaminhados às unidades de recebimento do sistema público municipal foram da ordem de 10.815 t/dia, tomando-se como referência o mês de dezembro de 2011 . O plano destaca que a maior parte dos resíduos coletados coube à competência da administração pública municipal, "à exceção dos resíduos de grandes geradores e das atividades de construção civil, que vinham sendo reaproveitados nos aterros para pavimentação de suas vias internas e recobrimento dos resíduos vazados" (Rio de Janeiro, 2012:7).

Quanto à composição percentual do lixo domiciliar recolhido na cidade, nota-se parte expressiva em que 40,99\% correspondem aos materiais passíveis de reciclagem, como metais, plásticos, vidros, papel e papelão. As frações restantes referem-se aos orgânicos (52,68\%) e aos restos de madeira e de tecidos, e a outros resíduos (6,33\%). Da totalidade de materiais recicláveis presente no lixo domiciliar, o plástico e papel papelão respondem por quase $90 \%$ desses materiais (Rio de Janeiro, 2012).

Quanto à destinação dos resíduos sólidos gerados na cidade do Rio de Janeiro, o PMGIRS aponta que em 2011 as unidades de disposição final de resíduos sólidos receberam, em média, 9.666 toneladas de lixo por dia do município do Rio de Janeiro. O lixo domiciliar 
(4.777 t/dia) acrescido do lixo público coletado (3.139 t/dia) alcançou o total de 7.916 t/dia (Rio de Janeiro, 2012:12).

\section{Resultados e discussão}

As cooperativas de catadores de materiais recicláveis estão sob o foco da gestão pública e das políticas públicas. Antes renegados às políticas higienistas, os catadores foram elevados a postos de atores estratégicos na execução de planos para a gestão RSU, notadamente após a sanção da PNRS.

Como a perspectiva deste trabalho se refere à compreensão das políticas públicas voltadas à coleta seletiva com foco no trabalho desenvolvido pelas cooperativas de catadores, foi imprescindível a participação desses atores nesta pesquisa, que se encontra mais amplamente discutida em Baptista (2013). De duas listas obtidas junto à Comlurb e SEA, foram escolhidas três cooperativas de catadores pertencentes à lista.

O critério de escolha foi fundamentalmente pela busca de cooperativas associadas à Federação das Cooperativas de Catadores de Materiais Recicláveis (Febracom) e que já tivessem participado de chamadas públicas com o Governo do Estado do Rio de Janeiro e/ou a Prefeitura da Cidade do Rio de Janeiro. No que toca ao primeiro critério - a associação com a Febracom - , optamos por ele pelo fato de buscar cooperativas que estivessem associadas política e institucionalmente a algum tipo de organização, em nível macro, de cooperativas. A Febracom, neste sentido, já conhecida entre diversas cooperativas, vem a confirmar um mínimo de organização entre as cooperativas. No que se refere ao segundo critério - participação em chamadas públicas - , optamos por ele pelo fato de se entrar em contato com cooperativas que já tivessem alguma aproximação com o poder público via prestação de serviços. Tal critério sustenta uma argumentação acerca de cooperativas que já tenham contato com o estado ou a prefeitura do Rio de Janeiro. Dos três empreendimentos pesquisados, uma está em processo de legalização; as outras são cooperativas, com estatutos formalizados.

As entrevistas realizadas aconteceram nos galpões das cooperativas, onde se pôde, inclusive, aplicar a técnica da observação. Antes das entrevistas foi perguntada a possibilidade de gravação de voz, o que foi permitido. Contudo, para não expor os(as) entrevistados(as), todos não foram identificados na transcrição das entrevistas. Por conta disso, a partir deste ponto, todos serão tratados como "Gestor", identificados como do empreendimento "A", "B" e "C".

Foi seguido um roteiro de entrevista pautado pela estrutura semiaberta (Vergara, 2009), sendo necessária algumas vezes a reformulação de perguntas e explicações sobre determinados itens.

A análise das entrevistas foi realizada com base na análise do conteúdo dos gestores de cooperativas. Como situado por Rocha e Deusdará (2005:307), a análise do conteúdo tem como objetivo "alcançar uma pretensa significação profunda, um sentido estável, conferido pelo locutor no próprio ato de produção do texto”. Por conta disso, há de se considerar a subjetividade do pesquisador. 
O Gestor A é uma mulher de 46 anos, com ensino fundamental completo e que foi trabalhar com a coleta seletiva quando estava desempregada. Tem experiência de 10 anos na coleta seletiva. Realizou cursos específicos para a gestão da cooperativa. Esse gestor tem uma personalidade de liderança carismática, marcando presença forte. "Participo de tudo", diz esse gestor. Também tem uma percepção prática e objetiva da coleta seletiva, assim como de sua funcionalidade, mas possui pouco conhecimento do processo político. No entanto, sabe das dificuldades em relação ao mesmo e tem forte posicionamento político.

O Gestor B é uma mulher de 61 anos, com ensino fundamental incompleto, que trabalha há mais de quatro décadas com a coleta seletiva na função de catadora. Tem amplo conhecimento técnico sobre o acondicionamento dos resíduos, tanto que não se percebeu cheiro de lixo no galpão, o que foi, inclusive, ressaltado pelo gestor. Dentre os gestores é o que tem mais profundo grau de mobilização política, incitando a necessidade de participação e organização das pessoas da cooperativa.

O Gestor C é um homem de 67 anos, com formação em nível superior em filosofia e mestrado em orientação educacional. Tem experiência de mais de duas décadas com a coleta seletiva. Também foi capelão na Marinha e está aposentado. Dentre os gestores é o que tem maior conhecimento sobre o processo político, sobre como uma política pública é criada, suas variáveis, atores, agentes e processos. É também o que mais critica o distanciamento entre aquilo que é pensado e aquilo que é executado. Paralelamente, é o mais enfático na questão de as cooperativas não serem chamadas no processo de formulação de políticas.

Após esta pesquisa de campo, sistematizamos as informações a fim de relativizar situações enfrentadas pelas cooperativas, mas, sobretudo, para identificar as perspectivas e os limites das políticas públicas voltadas à coleta seletiva, além das positividades e negatividades das cooperativas e oportunidades e ameaças enfrentadas pelas mesmas. As perspectivas se referem a possibilidades no sentido positivo. Quando mencionamos os limites, a orientação incide sobre as possibilidades negativas.

O maior limite está no estado de desamparo estrutural em que se encontram as cooperativas e que traduz todo o limite que as políticas públicas voltadas à coleta seletiva não conseguem alcançar. Ou, se conseguem alcançar, não são suficientemente pactuadas ou estruturadas para causar mudanças transformadoras efetivas sobre a realidade das cooperativas de catadores. Como criar políticas públicas em um cenário tão caótico, com múltiplas demandas? A estruturação das políticas perpassa pelo diálogo com as cooperativas para saber as urgências e necessidades imediatas.

É tudo. Infraestrutura também. As pessoas pra ver a cooperativa tem que ter o espaço, ter o lugar. E não é fácil não. Tem muitos lugares por aí que não é igual aqui. Hoje o sol tá lindo, mas quando chove... Alguma coisa eles tinham mais é que procurar a gente pra poder ajudar nisso. (Gestor A, 2013)

Tá sendo muito reaproveitado o material do Rio de Janeiro. E há três anos atrás não tinha essa opção. Eu sofri muito aqui nessa cooperativa, eu fui muito pisada, sabe o que é pisada? Por algumas pessoas da Prefeitura, eu não estou falando do nosso prefeito [Eduardo Paes], porque ele 
não sabia de nada (...). Então eu confio no meu presidente e na minha presidente, porque eu tive direto, eu falei diretamente olhando pra ele 'presidente o senhor tem que ver a situação que nós estamos passando, presidente, nós não tá aguentando mais'. Eu senti o que o povo sente na pele aqui no Rio de Janeiro, o sofrimento que a gente tava sentindo (...) Sempre naquela humilhação, pisada, morta. (Gestor B, 2013)

Agora, o governo, as políticas sociais, de resíduos e tudo isso, tá fantástica, tá no caminho certo. Precisa ser ajustado ao longo da caminhada, não são críticas, são pequenos ajustes como tudo precisa ser feito. Ajustes pra poder funcionar e azeitar todas as engrenagens (...). (Gestor C, 2013)

Essa questão também já foi ressaltada em trabalhos anteriores. Besen (2008:12) pondera que

no cerne das contradições os catadores defendem a sua autonomia plena e ao mesmo tempo subsídios governamentais temporários que viabilizem seu acesso ao trabalho formal, querem incluir muitos, no entanto, ainda incluem poucos, até porque muitos não querem ser incluídos.

Isso vem corroborar a ideia de que não há possibilidade de se criar políticas públicas em que atores fundamentais não façam parte das negociações. Falta a estrutura necessária para que as cooperativas tenham a capacidade plena para o desenvolvimento de suas atividades.

A maior perspectiva está no fato de que as cooperativas de catadores são agora atores visíveis dentro do sistema político. A criação de políticas públicas necessita considerar todos os atores, na medida do possível identificáveis, na formulação da política. A intervenção no sistema de gestão de resíduos sólidos precisa considerar as cooperativas de catadores. Do contrário não é uma política pública coerente, pois não traz agentes fundamentais que atuam sistematicamente na reciclagem e recuperação de materiais.

Agora, graças a Deus, que estas políticas todas estão sendo implantadas, muito bem implantadas e ela vai ter um tempo de maturação, de assimilar, tudo, pra começar a produzir frutos. Só que nós brasileiros somos imediatistas e queremos o fruto pra ontem. Não é bem assim que funciona a coisa. (Gestor C, 2013)

Precisa-se mudar a forma de visualizar as cooperativas. O limite está na visão de que as cooperativas são "coitadinhas". As cooperativas não são coitadinhas; são organizadas e estruturadas suficientemente para fazer frente a outros atores. Contudo, estão fragilizadas, ainda que apresentem certo grau positivo de estruturas e organização, mas também pontos que descompensam estas. Aqui o limite está no assistencialismo. As políticas públicas criadas não podem beirar pelo assistencialismo, por não mudarem as realidades das cooperativas. Aqui também se encontra a perspectiva: as cooperativas não querem esmola; não querem assistencialismo - elas querem dignidade e trabalho. Elas necessitam de recursos? Sim, mas não sob a forma de esmola. 
O ser humano precisa um salário bom e oportunidade de trabalho, ninguém precisa de bolsa pra sobreviver, isso daí não é questão social, isso não leva a nada. Você, é ao contrário, você afunda um pouquinho mais e acomoda um pouquinho mais eles nessa situação. Que o dia dele receber bolsa-família, eles faltam ao trabalho. Então parece até um contrassenso. Essas coisas são boas mas não devem ser assim... devem ser canalizadas, tem que remunerar e dar dignidade quando você trabalha, quando você faz a parte que a sociedade precisa que alguém faça. (Gestor C, 2013)

A segunda questão está na valorização do trabalho das cooperativas. A perspectiva está no fato de que as cooperativas vêm tendo uma maior valorização, até mesmo pelos próprios discursos dos gestores, quando dizem que têm orgulho de terem se sustentado do lixo ou que o lixo não é mais vergonha. Se surgem políticas como a PNRS, o Decreto no 5.940/2006, a Lei no 12.690/2012, são indícios de que o trabalho das cooperativas está sendo valorizado. Se há maior circulação de informações na mídia que citam a importância da coleta seletiva, é que o trabalho desenvolvido pelas cooperativas vem ganhando força. Por outro lado, o limite está na falta de institucionalização: como estruturar um sistema de coleta seletiva sem que as cooperativas possuam logística própria? Como estruturar, se não há educação formal sobre o tema nas escolas? Ou se é estimulado à cultura do consumo e do desperdício? Como organizar a coleta seletiva se o titular dos serviços públicos de limpeza também não está estruturado para tal? Nesse sentido, as políticas públicas precisam de ajustes, como citado por um dos gestores. Os políticos precisam sair de seus gabinetes e ir às cooperativas, ao titular dos serviços públicos de limpeza, às escolas, às universidades, ou seja, é uma construção conjunta que necessita de canais abertos e públicos institucionalizados para o diálogo e participação dos atores.

Os catadores... é uma profissão que surgiu de agora, muito recente e já tá regulamentada, como profissão, então isso demonstra, denota uma preocupação para que isso possa caminhar. Que a gente tá fazendo um trabalho, um trabalho mais ou menos difícil, não gosto de dizer isso, de trabalho sujo. Não é um trabalho sujo. Que essa conotação "suja" pareceria ilegal, não sei o que... não, é um trabalho em cima de resíduos, então é um trabalho "sujo" nesse sentido. (Gestor C, 2013)

(...) porque lixo era vergonha né? Hoje em dia você fala "eu trabalho na reciclagem" e todo mundo se orgulha. Eu me orgulho. Quando eu entrei mesmo no trabalho eu tinha até vergonha — "eu trabalho no lixo" (...) agora não. Agora eu tenho prazer em falar "eu trabalho na reciclagem", meio ambiente... Tá sendo um sucesso hoje em dia né? E também pra natureza também e pra tudo. (Gestor A, 2013)

O terceiro ponto recai sobre o governo Lula. De maneira especial, durante e após o seu governo, os catadores ganharam maior espaço. Aqui perspectivas e limites se compõem. Quais políticas públicas esperar após as cooperativas serem trazidas à arena? Entre $2006 \mathrm{e}$ 2010 surgiram políticas, tanto em âmbito federal, quanto estadual e municipal, sobre a coleta 
seletiva e a gestão dos resíduos sólidos. Surgiram planos municipais, estaduais e as primeiras inserções nos planos diretores. Mas o que esperar daqui em diante? A Lei no 12.690/2012, que reestrutura a organização das cooperativas, é um exemplo. Em 2010 começou a estruturação da coleta seletiva no Brasil - pelo menos formalmente. Em seguida, perceberam fragilidades no sistema, como a escamoteação das relações trabalhistas, a falta de segurança dos cooperados, a renda etc. A Lei no 12.690/2012 representa a tentativa de reparar erros e oferecer segurança aos catadores, mas, ao mesmo tempo, as cooperativas não têm recursos suficientes para atender aos dispositivos da lei. Aqui, a perspectiva de melhorar a situação da coleta seletiva é evidente. Aqui, o limite está presente, pois esta política não observou atores, tanto que o Movimento Nacional dos Catadores de Recicláveis (MNCR) lançou uma nota se manifestando contrariamente à lei. Não queremos assumir um posicionamento contrário ou favorável a essa lei, pois ela necessita de ponderação. O que queremos ressaltar é que surgirão mais políticas públicas voltadas ao tema; mas o que esperar dessas políticas?

Mas graças a Deus, depois da gestão aí do nosso prefeito [Eduardo Paes], da nossa presidente [Dilma Rousseff], do nosso presidente [Lula], mudou muito essas coisas, porque eu já estive em Brasília, já fui pra São Paulo, já fui pra Minas Gerais, eu já fui em todos os lugares, há dez anos correndo atrás do que tá acontecendo hoje, que vem melhorar a coleta seletiva. (...) mas graças a Deus agora tá melhorando muito devido a esse conhecimento do nosso presidente, porque quem vem dar a honra pra coleta seletiva foi o presidente Lula. O Lula foi quem apoiou os catadores. É que falou em Brasília que o catador era uma pessoa trabalhadora igual a um funcionário do banco, igual a pessoas que fizessem qualquer serviço, entendeu? (...) Em Minas Gerais, quando o presidente [Lula] chegou lá, mas a presidente [Dilma], nós explicou toda a situação, que todos os lugares estavam sendo beneficiados, a Bahia, o Ceará... Vitória, vários lugares já estavam sendo ajudados. As cooperativas estavam sendo todo mundo ajudado. São Paulo, também. Minas Gerais, eu estou lembrando assim aos pouquinhos, porque tem muitas que estão sendo beneficiadas através do nosso presidente Lula. Então devido à nossa briga, eu ano retrasado eu levei a bandeira do Rio de Janeiro e falei pro povo "olha gente, o Rio de Janeiro tá precisando que alguém tome uma solução dos catadores, porque os catadores só têm trabalhado e trabalhado e ninguém vê nada, ninguém vê nada, ninguém vê nada". (Gestor B, 2013)

O mais significativo dos problemas é a questão logística. Aqui também há perspectivas e limites. A falta de caminhões próprios da cooperativa é o limite crucial da operacionalização da coleta seletiva. Os gestores recusam material, pois não há como ir buscá-lo no momento exato em que há oferecimento do mesmo. Ao mesmo tempo não têm como escoar adequadamente os materiais recicláveis quando querem. As cooperativas precisam compartilhar quatro caminhões da Febracom para sua produção. As perspectivas, por outro lado, são evidentes, mas ainda insuficientes: a Febracom atua no auxílio às cooperativas, estruturando uma logística nas condições em que pode estruturar. Por outro lado, os gestores indicaram como limite a impossibilidade de obter empréstimos bancários para a compra de veículos. Aqui se questiona: como operacionalizar a coleta seletiva se as cooperativas não têm condições de estruturar 
a sua própria logística, adequada às suas necessidades? Percebeu-se que a falta de caminhão configura o par de algemas das cooperativas de catadores.

Olha, essas empresas grande podiam entregar o material pra gente, entendeu? E os caminhões são bem pouco. "O problema nosso é transporte." O que pega é que não dá pra gente atender tudo, porque fica muito transporte. Quando então gente paga a diária por fora. Ajudante não vale a pena, por que pelos materiais que têm vindo, sem valor. (Gestor A, 2013)

Nós estamos sendo muito é humilhados, humilhados, porque poxa, tinha pessoas da prefeitura que chegam aqui diziam "olha [entrevistada cita o próprio nome], qualquer hora a gente vai vir aqui vai fechar o galpão, olha fulana esse material aqui fora", aí eu digo "meu filho, é o pessoal que vem e joga pra gente", pois a gente não tem ninguém pra dar pra gente. Então a gente ia lá fora e tirava o material e levava pra dentro, reciclava e o restante manda botar fora "porque nós não tinha onde botar". Um caminhão pra levar o rejeito era $\mathrm{R} \$ 800,00$ que o cara cobrava ou a gente ganhava ou a gente largava por aí, ele dizia que ia dar multa e a gente ia levar multa, porque a gente não tinha condições de pagar um caminhão, os R\$ 800,00. (Gestor B, 2013)

Por exemplo, esse caminhão aí, se ele foi pra Itaguaí, tá custando pra ele R \$ 150,00 a tonelada. Ele leva em média três toneladas, $\mathrm{R} \$ 450,00$ custo de... aí tem o óleo, tem o motorista, tem o desgaste... Então você vê: é um trabalho que a sociedade tem que arcar com isso que é o que a gente produz. Então esse custo operacional é que dificulta o nosso trabalho. Agora, como poderia ser resolvido isso? Quando joga aqui esse material ou os outros materiais, a gente deveria ser remunerado pra poder compensar. Porque, por exemplo, se eu pegar um caminhãozinho nosso, pra ir até o centro da cidade, pegar, vamos dizer assim, no máximo, no máximo, $100 \mathrm{~kg}$, $200 \mathrm{~kg}, 300 \mathrm{~kg}$, nós estamos pagando pra trabalhar. "Porque o custo do combustível, a diária do motorista, o desgaste do caminhão, quase que não compensa." Então ele roda o dia inteiro, pra chegar no final do dia, aquilo o que é arrecadado não dá nem pra cobrir as despesas. (Gestor C, 2013)

Registre-se que houve mudança real na coleta seletiva após a PNRS. Como exposto anteriormente, isso traz perspectivas e limites no sentido de o que se esperar daqui em diante. Mas há também uma ameaça: percebe-se que houve mudança, mas não se reconhece a PNRS. Neste caso, qual a contribuição explícita da PNRS? Em uma análise densa do conteúdo indicado nas falas dos gestores, não houve mudança a partir da PNRS, pois ela não é percebida pelos mesmos. Quando indagados se conheciam a PNRS, eis as respostas dos gestores: "Mais ou menos, porque não tenho tempo de ir pra esses lugares, eu vejo mais aqui" (Gestor B, 2013); "Sim, engavetada. Agora é isso aí" (Gestor A, 2013).

Pelo discurso dos gestores, notadamente na visão do gestor $\mathrm{B}$, essa mudança adveio com o governo Lula, especificamente com a alteração da agenda social. Como limite se destaca a não percepção da PNRS enquanto política pública. Nesse caso, como pactuar a gestão compartilhada, se uma política pública essencial não é percebida pelos policytakers? A perspectiva é que houve mudança. Há o sentimento e a percepção real de que houve mudança. E 
a partir da percepção de mudança, podem vir novos questionamentos e demandas por mais mudanças ou por ajustes no processo, como salientado por um dos gestores. Mas esse é um processo longo e que exige maturação e tempo para assimilação.

Trouxe, porque é obrigado a doar material pra gente. Mesmo assim está que 80\%, tá andando num ritmo direitinho, chamando a gente pra poder doar os materiais. (Gestor A, 2013)

(...) foi bom. Foi bom porque é onde as pessoas já estão conhecendo alguma coisa (...). É por isso que eu digo, essas coisas veio mudar de três anos pra cá. De três anos pra cá que veio mudar isso aí. (Gestor B, 2013)

Ela vem fazendo a diferença porque há uma conscientização, uma preparação. (Gestor C, 2013)

Não obstante, existem leis que procuram equilibrar a correlação de forças. No caso da coleta seletiva e da gestão dos RSU, o lado mais fraco está nos catadores. Lei no 12.690/2012 é uma clara proposta de reorganizar a correlação de forças. Esta é uma perspectiva. A proposta é boa; traz segurança; traz a possibilidade de salvaguardar as condições de vida e de trabalho dos catadores. Como diz um dos gestores: "é fantástico" (Gestor C, 2013). É uma proposta que é perfeita, mas não perguntaram às cooperativas se as mesmas teriam condições de arcar com a política. Não perguntaram, pois se perguntassem saberiam que a resposta seria negativa. Aqui está o limite: cria-se uma política com a melhor das intenções, porém mal construída, pensada e estruturada, pois não olha para aqueles que aplicarão a política: as cooperativas. Não é a primeira vez que existe uma política com a melhor das intenções e, por ter a melhor das intenções, talvez não seja a que possa ser aplicada no momento. Carece, como situado por um dos gestores, de um tempo de maturação e assimilação. A PNRS é recente, foi sancionada em 2010 e, enquanto essa pesquisa está em desenvolvimento, estamos no ano de 2013 e ainda não houve tempo hábil para assimilação. Lembrando o sentido de incrementalismo da política, isso é o que está acontecendo com a PNRS, a criação de políticas que visam ajustar pontos falhos não observados. Mas necessita-se de um tempo de maturação.

A pior coisa que tem, é você ter os técnicos que sentam nos gabinetes e produzem as ideias, coisas que são boas, fantásticas, são necessárias, mas entre aquilo o que é produzido num gabinete àquilo que é a realidade tem um distanciamento muito grande. Então talvez se houvesse esse casamento de pegar algumas coisas da base pra poder levar e aperfeiçoar, então isso aí seria fantástico. Porque é um trabalho comum de todos. Agora, o governo, as políticas sociais, de resíduos e tudo isso, tá fantástica, tá no caminho certo. Precisa ser ajustado ao longo da caminhada, não são críticas, são pequenos ajustes como tudo precisa ser feito. Ajustes pra poder funcionar e azeitar todas as engrenagens. (Gestor C, 2013)

A próxima consideração está na evolução positiva da renda das cooperativas. Aqui, os gestores foram unânimes: houve melhora. O que pode ser explicado principalmente com 
a obrigatoriedade não só de órgãos públicos, mas de outros geradores de resíduos, como a indústria e o comércio, de dispor de seus materiais. Segundo os gestores, o trabalho tende a crescer, assim como a renda. Aqui estaria a perspectiva, pois junto à renda os gestores situaram que procuram investir em maior conforto e benefícios aos cooperados, a exemplo de cursos, palestras, projetos que envolvam as famílias dos cooperados e a comunidade, além de cestas básicas. O limite, como situado pelos gestores, está na infraestrutura das cooperativas, pois as mesmas não podem atender a todos e as cooperativas não possuem logística adequada. Esse aumento da renda chegará a um limite, devido à falta de investimentos. É uma análise simples: a cooperativa tem uma capacidade instalada de operação, ou seja, uma capacidade máxima de recuperar uma quantidade certa de materiais. Essa capacidade instalada de operação permite que se alcance um patamar máximo de renda que pode ser gerada. Não havendo investimentos na infraestrutura operacional da cooperativa ou um incremento da técnica aplicada, a renda não aumenta, à exceção de um aumento do valor dos materiais no mercado; aí, nesse caso, o aumento se daria não pela capacidade da cooperativa, mas por oscilações do mercado. Notadamente, esta melhora da renda se deveu ao aumento do volume de materiais recebidos. Alguns gestores procuram, com essa melhora percebida, dar maior conforto aos cooperados, oferecendo coisas que antes não existiam.

As empresas não estavam doando assim. Doavam mais quando queriam. Ligavam e falavam: "você aceita material?". Agora não, elas são obrigadas. Tanto que elas têm o manifesto [de resíduos]. Elas procuram pra doar o material pra gente. Tá melhorando bastante. (...) Melhorou a renda. E mais emprego também. Começamos com 15 [pessoas]. E agora já deve estar com 70, 80 [pessoas] já. (Gestor A, 2013)

Eu saía com R\$20,00, todo mundo aqui. Uma mixaria de dinheiro. Você vê o PET, o preço era lá embaixo, hoje em dia graças a Deus as coisas melhoraram mais. Já tendo mais... um precinho melhor pras coisas. (...) Melhorou a renda. Melhorou porque antes a gente tinha $\mathrm{R} \$ 420,00, \mathrm{R} \$$ 500,00 . Nós não tirava isso, nós tirava nem $\mathrm{R} \$ 200,00$. Nem R \$ 100,00 vem dizer por semana. Eu saía daqui arrasada, arrasada. Não tinha nada. A dificuldade nossa aqui foi muito grande. Muito grande. Muito grande. Muito grande. E espero em Deus, vamos esperar em Deus, que ele é santo vivo e poderoso. (Gestor B, 2013)

(...) hoje nós estamos pagando, pra cada um que produz $\mathrm{R} \$ 0,10$ o quilo. Você poderia dizer "é pouco". É... relativamente pouco, mas às vezes nós vendemos o material a 12 , a 15 , às vezes baixa a oito, mas eu continuo pagando os 10 centavos, mas tem materiais como o PET, tudo isso, que estão muito acima disso, $\mathrm{R} \$ 1,00$. Mas aí também você tem café da manhã, almoço, lanche, jantar e cesta básica. Então tudo isso é custo. E precisa ser tirado daqui, e precisa ser feita essa química toda. Estamos estudando pra gente remunerar por preço diferenciado por cada material. (Gestor C, 2013)

Por fim, o que podemos depreender a partir da pesquisa é que a PNRS é uma política pública que traz instrumentos que não são percebidos em sua totalidade pelos atores envolvi- 
dos, o que implica sua não pactuação e, por consequência, não utilização plena das vantagens induzidas pela política. A pesquisa de campo junto aos gestores foi enfática: eles têm pouco conhecimento sobre o conteúdo da PNRS, mas sabem todo o processo técnico da coleta seletiva e da gestão dos resíduos. Só que as cooperativas apresentam conjuntura instável de estrutura. A PNRS não é pactuada plenamente por todos os atores e, dessa forma, perde a capacidade de inclusão social. É uma política que traz perspectivas positivas de mudanças transformadoras positivas da realidade social, mas que possui entraves que representam limites a essa mudança. Não se quer dizer também que a PNRS não seja pactuada somente pelos catadores, mas que a mesma não sofre um processo de pactuação entre os atores.

Há um distanciamento entre os gabinetes dos formuladores da política e os galpões da cooperativa. Indica-se a necessidade de mudanças no debate, planejamento, condução e avaliação de políticas públicas, assim como a articulação, capacitação e participação de todos os envolvidos nas políticas, representando o sólido exercício do controle social e a capacidade de interferência de todos os envolvidos e hierarquias que fazem parte desse processo complexo.

\section{Considerações finais}

A PNRS voltou ao debate público com maior abertura política, com a ampliação das normas que assegurassem a participação política, mas, fundamentalmente, com a reorganização da agenda social, trazida com o governo Lula. A incorporação do catador, aqui no entendimento pela lei como preferencialmente associado a uma associação ou cooperativa, já dimensiona a questão social indicada na PNRS. Essa incorporação social representa a reivindicação à participação política e à representatividade no espaço público, político, social, econômico e cultural.

O lixo (agora resíduo) somente foi percebido como dotado de valor quando implicou percepções sociais, econômicas, políticas, culturais e ambientais. Podia-se extrair valor daquilo que já foi extraído, ou melhor, recuperar valor. É aqui que entram o catador e as cooperativas. Quem fará o trabalho sujo? Serão os titulares de limpeza pública? Serão os consumidores? Serão as empresas? Nenhum dos três. Quem fará o trabalho sujo da segregação; o trabalho insalubre de estar em contato com materiais que podem causar doenças; o trabalho de respirar o odor do "lixo dos outros"; ou seja, quem fará o trabalho de recuperar o valor daquilo que foi usado e descartado pelos outros? Seriam os catadores.

Por isso os catadores foram elevados a atores de importância estratégica para a gestão de resíduos. Não foi caridade; não foi visão solidária; não foi atenção com as camadas mais pobres. Foi uma clara percepção de se utilizar uma mão de obra disponível e que possui conhecimento técnico na sua atuação.

É nas oportunidades dessas janelas que se tem a possibilidade de intervenção na realidade social. Aproveitemos essa política para resgatar a dignidade das pessoas que trabalham com o lixo. Nesse ponto foram incorporadas várias políticas, diretrizes e instrumentos que envolvem as cooperativas de catadores e o catador individual.

Mas aqui novamente trazem-se as verdadeiras intenções de uma política. Sim, tem-se uma política amparada por outras e que procura institucionalizar uma gestão compartilhada 
e, principalmente, institucionalizar a coleta seletiva solidária com a participação e inclusão social de catadores. Sim, tem-se a política (no sentido de policy), mas não a política (no sentido de politcs), ou seja, temos a regra geral, mas não as regras específicas que deveriam sustentar esta política no mais alto grau.

Aqui é que está o perigo: o de se ter uma política pública, mas não haver a organização política e institucional em seu torno. Aqui, uma política real se torna uma política simbólica, pois está presa em si mesma, algemada em burocracias, em falta de consenso, na impossibilidade de diálogo e participação política. Essa á a história da PNRS. E essa é sua vida.

A PNRS traz medidas e projetos que podem maximizar a aplicação da própria política com ganho socioeconômico para os catadores de materiais recicláveis. Contudo, a PNRS é uma política pública que traz instrumentos que não são percebidos em sua totalidade pelos atores envolvidos, o que implica sua não pactuação e, por consequência, não utilização plena das vantagens induzidas pela política.

A pesquisa de campo junto aos gestores evidenciou o desamparo estrutural em que as cooperativas se encontram. A coleta seletiva necessita de aporte do poder público. As cooperativas de catadores estão vivendo uma situação de desamparo estrutural, ainda que estejam se estruturando e se organizando paulatinamente. Elas necessitam de tudo: auxílio jurídico no que diz respeito a um ambiente próprio, para que não sejam ameaçadas de despejo; auxílio financeiro, para que possam fazer reformas estruturais nos galpões e que possam obter máquinas e equipamentos; auxílio cultural e educacional, para que possam difundir a cultura do cooperativismo e melhorar suas técnicas de segregação; auxílio social, para que sejam capazes de estruturar ações voltadas aos cooperados e que possam estendê-las para as suas famílias; auxílio logístico, com o objetivo de combater o gargalo fundamental que é a falta de transporte; e auxílio político, para que possam reequilibrar as forças políticas e sejam capazes de se fazerem ouvidas pelos agentes públicos.

Mas as políticas não são condições suficientes para a resolução de problemas públicos. As políticas são condições necessárias a todo um ordenamento que envolve a sua pactuação. Esse é o processo por meio do qual as políticas públicas são pensadas, elaboradas, percebidas, implementadas, executadas e avaliadas conjuntamente pelos atores políticos, governamentais e não governamentais, com o apoio de instituições e espaços de negociação política abertos e estimulados à participação. Necessita-se do reconhecimento das conexões envolvidas na política pública e principalmente a consideração da mesma como meio para as mudanças transformadoras da realidade social.

Necessitam-se instituições, ou seja, normas conhecidas por todos e que induzem à participação política. Ao mesmo tempo, as condições de igualdade na construção das políticas precisam ser asseguradas nos espaços de negociação. Não há como criar políticas públicas efetivas se os atores não possuem canais abertos e públicos para o diálogo e a negociação. As políticas públicas que têm como foco determinados atores que não participaram em sua construção não são políticas públicas. São, no mínimo, medidas intervencionistas com caráter público, mas sem o "público" que deveria ter parte basilar de participação. 


\section{Referências}

ABRELPE. Associação Brasileira de Empresas de Limpeza Pública e Resíduos Especiais. Panorama dos resíduos sólidos no Brasil, 2011. São Paulo: Aprelbe, 2012.

BAPTISTA, Vinícius F. Perspectivas e limites das políticas públicas voltadas à coleta seletiva de resíduos sólidos urbanos: análise a partir da Política Nacional de Resíduos Sólidos e de gestores de cooperativas de catadores de materiais recicláveis no município do Rio de Janeiro. Dissertação (mestrado em políticas públicas e formação humana) - Faculdade de Educação, Universidade do Estado do Rio de Janeiro, Rio de Janeiro, 2013.

BESEN, Gina R. Sustentabilidade dos programas de coleta seletiva com inclusão social: avanços, desafios e indicadores. In: ENCONTRO NACIONAL DA ASSOCIAÇÃO NACIONAL DE PÓS-GRADUAÇÃO E PESQUISA EM AMBIENTE E SOCIEDADE, ANPPAS. Brasília, DF: ANPPAS, 4-6, jun. 2008. Anais... p. 1-14. Disponível em: <www.anppas.org.br/encontro4/cd/ARQUIVOS/GT6-403-13520080509143212.pdf>. Acesso em: 2 dez. 2011.

BOSI, Antonio P. A organização capitalista do trabalho "informal": o caso dos catadores de recicláveis. Rev. Bras. Ci. Soc., São Paulo, v. 23, n. 67, p. 101-116, jun. 2008. Disponível em: <www. scielo.br/scielo.php? script $=$ sci_arttextepid $=$ S0102-69092008000200008elng $=$ enenrm $=\mathrm{iso}>$. Acesso em: 7 mar. 2012.

BRASIL. Lei $n^{\circ}$ 12.305, de 2 de agosto de 2010. Institui a política nacional de resíduos sólidos; altera a Lei no 9.605, de 12 de fevereiro de 1998; e dá outras providências. Disponível em: <www.planalto. gov.br/ccivil_03/_ato2007-2010/2010/lei/112305.htm>. Acesso em: 2 dez. 2010.

CONCEIÇÃO, Marcio M. Os empresários do lixo: um paradoxo da modernidade: análise interdisciplinar das cooperativas de reciclagem de lixo. Campinas, SP: Átomo, 2003.

GESTOR A. Entrevista I [16 maio 2013]. Entrevistador: Vinícius Ferreira Baptista. Rio de Janeiro, 2013. 1 Arquivo .mp3 (35 minutos). In: BAPTISTA, Vinícius F. Perspectivas e limites das políticas públicas voltadas à coleta seletiva de resíduos sólidos urbanos: análise a partir da Política Nacional de Resíduos Sólidos e de gestores de cooperativas de catadores de materiais recicláveis no município do Rio de Janeiro. Dissertação (mestrado em políticas públicas e formação humana) — Faculdade de Educação, Universidade do Estado do Rio de Janeiro, Rio de Janeiro, 2013.

GESTOR B. Entrevista II [28 maio 2013]. Entrevistador: Vinícius Ferreira Baptista. Rio de Janeiro, 2013. 1 Arquivo .mp3 (52 minutos). In: BAPTISTA, Vinícius F. Perspectivas e limites das políticas públicas voltadas à coleta seletiva de resíduos sólidos urbanos: análise a partir da Política Nacional de Resíduos Sólidos e de gestores de cooperativas de catadores de materiais recicláveis no município do Rio de Janeiro. Dissertação (mestrado em políticas públicas e formação humana) — Faculdade de Educação, Universidade do Estado do Rio de Janeiro, Rio de Janeiro, 2013.

GESTOR C. Entrevista III [29 maio 2013]. Entrevistador: Vinícius Ferreira Baptista. Rio de Janeiro, 2013. 1 Arquivo .mp3 (46 minutos). In: BAPTISTA, Vinícius F. Perspectivas e limites das políticas públicas voltadas à coleta seletiva de resíduos sólidos urbanos: análise a partir da Política Nacional de 
Resíduos Sólidos e de gestores de cooperativas de catadores de materiais recicláveis no município do Rio de Janeiro. Dissertação (mestrado em políticas públicas e formação humana) — Faculdade de Educação, Universidade do Estado do Rio de Janeiro, Rio de Janeiro, 2013.

IBGE. Instituto Brasileiro de Geografia e Estatística (IBGE). Pesquisa nacional de Saneamento básico - 2008. Rio de Janeiro: IBGE, 2010.

JARDIM, Arnaldo; YOSHIDA, Consuelo; MACHADO FILHO, José V. (Ed.). Política nacional, gestão de gerenciamento de resíduos sólidos. Barueri, SP: Manole, 2012.

KRUEGER, Guilherme. Cooperativas de trabalho na terceirização. Belo Horizonte: Mandamentos, 2003.

LEITE JUNIOR, Alcides D. Desenvolvimento e mudanças no estado brasileiro. Florianópolis: Departamento de Ciências da Administração/UFSC; [Brasília]: Capes; UAB, 2009.

MATIAS-PEREIRA, José. Curso de administração pública: foco nas instituições e ações governamentais. 3. ed. São Paulo: Atlas, 2010.

PEREIRA, Maria C. G.; TEIXEIRA, Marco A. C. A inclusão de catadores em programas de coleta seletiva: da agenda local à nacional. Cad. EBAPE.BR, v. 9, n. 3, p. 895-913, set. 2011. Disponível em: <www.scielo.br/scielo.php?pid=S1679-39512011000300011escript $=$ sci_arttext $>$. Acesso em: 22 abr. 2012

RIBEIRO, Helena et al. Programas municipais de coleta seletiva de lixo como fator de sustentabilidade dos sistemas públicos de saneamento ambiental na RMSP. In: SEMINÁRIO INTERNACIONAL DE ENGENHARIA DE SAÚDE PÚBLICA, III, 2006, Fortaleza. Brasília: Fundação Nacional de Saúde, 2006. p. 123-130 apud BESEN, Gina R. Sustentabilidade dos programas de coleta seletiva com inclusão social: avanços, desafios e indicadores. In: ENCONTRO NACIONAL DA ASSOCIAÇÃO NACIONAL DE PÓS-GRADUAÇÃO E PESQUISA EM AMBIENTE E SOCIEDADE, ANPPAS. Brasília, DF: ANPPAS, 4-6, jun. 2008. Anais... p. 1-14.

RIO DE JANEIRO [GOVERNO DO ESTADO]. Decreto no 40.645/07 de 08 de março de 2007. Institui a separação dos resíduos recicláveis descartados pelos órgãos e entidades da administração pública estadual direta e indireta, na fonte geradora, e a sua destinação às associações e cooperativas dos catadores de materiais recicláveis, e dá outras providências. Disponível em: <www.coletasolidaria. gov.br/menu/legislacao/Decreto\%2040.645\%20-\%20RJ.pdf/view>. Acesso em: 30 abr. 2012.

RIO DE JANEIRO [GOVERNO DO ESTADO]. Lei $n^{\circ}$ 3.755, de 07 de janeiro de 2002. Lei La Provita. Autoriza o Poder Executivo a financiar a formação de cooperativas com a finalidade que menciona. Disponível em: <http://alerjln1.alerj.rj.gov.br/contlei.nsf/01017f90ba503d61032564fe0066ea5b /879ee96c2e23964203256b3b006b0a54?OpenDocument>. Acesso em: 30 abr. 2012.

RIO DE JANEIRO [GOVERNO DO ESTADO]. Lei no 4.191, de 30 de setembro de 2003. Dispõe sobre a política estadual de resíduos sólidos e dá outras providências. Disponível em: <http://alerjln1. alerj.rj.gov.br/contlei.nsf/0/cf0ea9e43f8af64e83256db300647e83?OpenDocument>. Acesso em: 30 abr. 2012. 
RIO DE JANEIRO [PREFEITURA DA CIDADE]. Plano Municipal de Gestão Integrada de Resíduos Sólidos da Cidade do Rio de Janeiro: agosto 2012 — agosto 2016. Rio de Janeiro, 2012. Disponível em: <www.rio.rj.gov.br/web/smac/exibeconteudo?article-id=3035082>. Acesso em: 14 dez. 2012.

ROCHA, Décio; DEUSDARÁ, Bruno. Análise de conteúdo e análise do discurso: aproximações e afastamentos na (re)construção de uma trajetória. Alea, v. 7, n. 2, p. 305-322, jul./dez. 2005.

SEA. Secretaria de Estado do Ambiente do Governo do Estado do Rio de Janeiro. Disponível em: <www.rj.gov.br/web/sea/>. Acesso em: 16 dez. 2012.

VERGARA, Sylvia C. Métodos de coleta de dados no campo. São Paulo: Atlas, 2009.

Vinícius Ferreira Baptista é mestre em políticas públicas e formação humana e professor assistente do Departamento de Ciências Administrativas e Contábeis da Universidade Federal Rural do Rio de Janeiro (UFRRJ). E-mail: viniciusferbap2007@hotmail.com. 